\title{
A Proposed Model for Maximizing Broadband Penetration with Submarine Cable in Nigeria
}

\author{
Bourdillon Omijeh $^{1 *} \quad$ Chukwunomso Chukueggu ${ }^{2}$ \\ 1.Department of Electronic and Computer Engineering, University of Port Harcourt, PMB 5323, Port Harcourt, \\ Rivers State, Nigeria \\ 2.Centre for Information and Telecommunications Engineering, , University of Port Harcourt, PMB 5323, Port \\ Harcourt, Rivers State, Nigeria
}

\begin{abstract}
This publication is purely research and accumulated intellect based. The bottom up approach adopted in this research was focused on the Bandwidth Implications of Submarine Cable to Broadband Development in Nigeria. The study tried to pinpoint some underlying fundamental issues limiting the development of Fibre Broadband in Nigeria. The various sources of undersea cables and there various capacities were well evaluated as well as the socio economic importance of broadband and its numerous applications. Other sources of broadband were also highlighted, with strategies on how to increase broadband penetration in Nigeria. The economic implication of bandwidth and its relationship with national development, was well introduced using the 2016 human development report by United Nations Development Program. Analytical presentation of a proposed model for an interconnected long haul national backbone was also presented with the immerse benefits listed out. The study came to a conclusion with strong summarized recommendations followed by references.
\end{abstract}

Keywords: Backbone, Penetration, Undersea Cable, Broadband.

DOI: $10.7176 / \mathrm{NCS} / 12-03$

Publication date: January $31^{\text {st }} 2021$

\subsection{Introduction}

Undersea cables are special optical fibre cables laid on the ocean bed using specialized cable laying ships, with the aim of providing access to the telecommunications network of different countries separated by large bodies of water. Undersea cables form an integral part of the global telecommunications network structure (Forden, 2015). Over $95 \%$ of global communication is transmitted by undersea cables, showing the magnitude of the sensitive roles they play in maintaining global connectivity and preference they enjoy compared to other long distance modes of transmission like satellite communication. With the massive ever growing need for seamless broadband transmission all over the world, undersea cables have proven to be a reliable and ready solution to efficient sharing of communication network assets amongst nations due to their ability to accommodate large amounts of data and a capacity to transmit at speeds of up to $100 \mathrm{Gbps}$ (Forden, 2015). They are built to withstand nature's forces while ensuring that connectivity is uninterrupted over long periods of time.

The origin of undersea cables can be traced back to 1850 when the first undersea cable was laid from England to France. However in 1858 the first transatlantic submarine telegraph cable was laid between Newfoundland and Ireland. It was made up of a copper core which is able to transmit signals and coated with rubber to insulate it. It was used to send a telegraph from Queen Victoria to President Buchanan with a delivery time of 17 hours and 40 minutes (Geere, 2011). Through a series of dedicated effort and constant innovation by scientists, the undersea cable system has improved over the years to meet up with the unending demand for faster communication across borders.

Modern undersea cables are built with optical fibre technology, which enhances transmission using Wavelength Division Multiplexing (WDM) (Forden, 2015). This process allows multiple signals to be transmitted using their electromagnetic optical wavelengths on a shared cable connection. Optical fibre repeaters are also added to the cable to further amplify the signals being transmitted.

Investments in Undersea cables has drastically skyrocketed with private companies realizing the need for better communications infrastructure has led online giants such as Google, Microsoft and Facebook to dive into owning undersea cables independently which is different from the norm of governments and consortiums being the primary investors and operators of undersea cables.

Nigeria has benefitted from the growing global network of undersea cables, and currently boasts of 5 undersea cables by different operators namely, ACE, MAIN ONE, SAT-3/WASC, WACS and GLO-1 cables with landing points all located in Lagos state. These cables provide a combined capacity of over 14.9 Tbps, giving Nigeria the needed broadband infrastructure for growth and development in finance, commerce, governance, education and health sectors of the country. Nigeria has recorded a decline in broadband rates for internet users due to competition amongst cable operators to reduce whole sale broadband prices as an incentive to attract more customers (Kazeem, 2016). This goes to highlight the strategic roles and value undersea cable have to play in Nation building and socio-economic development. However there is still a lot of work to be done as broadband 
penetration is still not at optimum levels and the bandwidth made available by undersea cables is still underutilized. Broadband penetration in Nigeria currently sits at 21 percent while internet penetration is at 43 percent (EMPEA, 2014), which is not a positive reflection of the resources, investments, the available bandwidth and untapped opportunities presented by the undersea cables we have on our shores.

\subsection{Related Works}

The unending series of innovations and research put into the production of undersea cables have continued to transform the pace and zest in telecommunication on a global scale. In this paper, past works and publications related to the subject of study which includes related works on undersea cables and Broadband penetration in Nigeria and parts of Africa were carefully evaluated and analyzed. The reviewed literatures were gotten from Journal publications, articles, web publications and online newsletters.

\subsection{The Undersea Cable Boom in Sub-Saharan Africa}

The above paper (Forden, 2015) assessed the investments made by governments, consortiums and private companies in integrating undersea cables into the Sub-Saharan telecommunications network as part of efforts to boost economic viability of the region. It is the opinion of the author that Africa being left of the undersea cable boom that took place in the late 1990's, is yet to fully realize the potentials and benefits of international telecommunications connectivity with Sub-Saharan Africa of which Nigeria is a part of barely contributing 0.2 percent of the global telecommunications bandwidth between 2004 - 2009. However the author further points out that over \$3 billion dollars have been spent on the deployment of undersea cable networks in Africa between 2007 - 2012 which indicates a massive surge in investments and investor confidence in African communications networks. The author goes on to list out obstacles that have restricted sub-Saharan Africa from experiencing high demand in internet services. Citing low per capita incomes as a factor that will users from owning a personal computer or smartphone. Other obstacles listed are low bandwidth due to $2 \mathrm{G}$ networks provided by mobile network providers and lastly unreliable dynamic networks.

It is not out of place to point out that the authors assumptions were not totally accurate because despite the low per capita income mobile telecommunications companies have designed smartphones and personal computer for low income earners to ensure that no one is left out to digital divide. Also most parts of sub-Saharan Africa currently are being integrated with 4G LTE network packages by different mobile network providers, allowing subscribers to experience standard broadband services as seen in other parts of the developed world.

The author did not assess the profits made on investments in African undersea cable networks neither did he analyze policies and regulations that's have affected the viability of investments in Sub- Saharan Africa.

\subsection{The Poor State of Broadband in Nigeria: An Impediment to National Development and Globalisation} This paper (Ariyo \& Olaojoyetan, 2013) evaluates Broadband penetration in Nigeria using to the 2013 Global Information Technology Report (GITR) by the World Economic Forum as a bench mark. It reveals that Nigeria being ranked as no 113 in the world has a very low Network readiness Index (NRI) of 3.27 which is disappointing when compared to Ghana (no. 95) with NRI of 3.51 and South Africa (no. 70) with NRI of 3.87. The paper also takes a look at the present state of undersea cables in Nigeria and goes on to further pinpoint, some of the issues and problems hindering broadband penetration in the country. Listing high cost of procuring right of way, multiple taxation and lack of adequate power supply as part of the critical issues that has adversely affected broadband penetration in Nigeria. It is the position of the author that an increase in broadband will result in a commensurate increase in national economic growth. Giving reference to the World Bank information and communications report of 2009, it shows that developing countries experienced 1.38 percent increase in economic growth for every 10 percent points of broadband penetration. The paper however does not give insight on polices and regulations that have poorly affected investments in broadband services. Neither does the authors examine the applications and services offered by undersea cables and broadband respectively.

\subsection{Fibre Broadband Development In Nigeria: A Catalyst To Economic Growth And Social Development} This paper (Ariyo et al, 2014) reviews the history of broadband development laying emphasis on preceding technologies such as Dial up Internet and Asymmetrical Digital Subscriber Line (ADSL). It goes on to define the individual properties of fibre broadband with respect the components that make up fibre optic networks.

The paper does not give a holistic view of fibre broadband development in Nigeria as most of the references are based on developments in the United Kingdom. Furthermore there is little information on the history of broadband in Nigeria and milestones which has helped to shape the broadband infrastructure we have today. Therefore readers cannot draw a comprehensive conclusion as regards that statutory factors that have laid the ground work for fibre broadband from this paper. However issues pointed out by the authors such as the lack of an interconnected backbone, and the continuous existence of a redundant NITEL as a national operator are critical issues that have contributed to the slow pace and low penetration of broadband in Nigeria. Stating The 
Conversion Technology Experts report of 2014, the paper notes that Nigeria's broadband penetration remains at 6 percent while internet penetration is between 28 to 33 percent.

\subsection{Lowering the costs of International Bandwidth in Africa}

This paper (Jensen, 2006) describes bandwidth as the Life-blood of the world's knowledge economy. It blames lack of low cost communication needed by African nations to improve social economic development on the high cost of international connections to global telecommunications backbones. Which is much higher in Africa compared to Europe and North America. As part of the issues contributing to the slow pace of bandwidth availability in Africa, the paper decries the monopoly created by the consortium based deployment model in the SAT3/WASC/SAFE cable which has only succeeded in keeping the cost of bandwidth on the rise in SubSaharan Africa. Despite the fact that it's the region with the highest unmet demand for telecommunication services. The paper clamours for cost based pricing and operations model where the undersea cable and landing points are operated on a non- profit basis. The author suggests that a special purpose vehicle (SPV) which will serve as an investment vehicle and operator, be established to operate fibre facilities with the objective of facilitating profits made by participating companies and also allow the participation of new operators that might bring funding and other benefits to the table. As a solution curtail the strong hold of monopolies on telecommunications networks, the author proffers a viable structure which is divided into two parts where the national cable landing points are managed by a national association of bandwidth providers, and the cable will be owned by a mix of operators including private and public investors. This creates a competitive environment needed for effective pricing of bandwidth allowing the end user to enjoy more value from telecommunications services.

\subsection{Submarine cable Design Analysis}

The propagation of light in optical fibre is hinged on the principle of refraction, which involves the change of direction in a wave as it travels resulting from a change in medium of propagation (Wikipedia, 2017).

The Refractive index being the ratio of light velocity in a vacuum to light velocity in a medium (Senior, 2009) is a measure of angles of incidence and angles of refraction created by bending light waves.

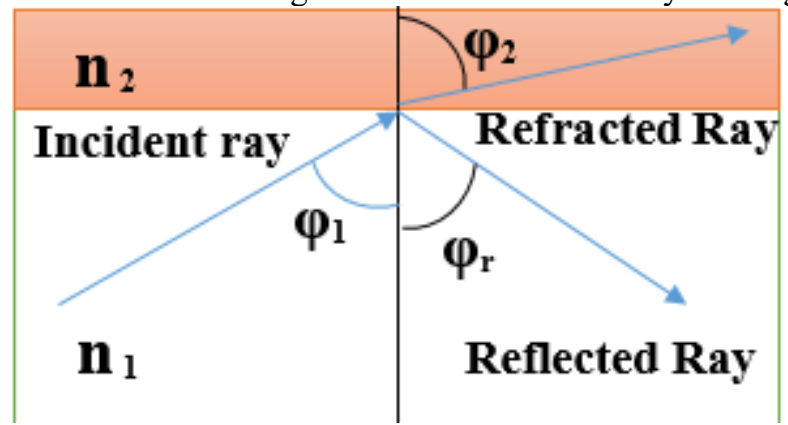

FIGURE 3. 1 Light Propagation in Optical Fibre

\subsection{Snell's Law of Refraction}

The principal law guiding the refraction of light waves propagation through a medium states that:

Total Internal Reflection

$$
\begin{aligned}
& \mathbf{n}_{1} * \sin \varphi_{1}=\mathbf{n}_{2} * \sin \varphi_{2} \\
& \mathbf{n}_{1}>\mathbf{n}_{2} \Rightarrow \varphi_{1}<\varphi_{2}
\end{aligned}
$$

$$
\text { Critical angle: } \begin{aligned}
\varphi_{c} \Rightarrow & \varphi_{2}=\pi / 2 \\
\varphi_{c} & =\arcsin \left[n_{2} / n_{1}\right]
\end{aligned}
$$

If $\varphi_{1}>\varphi_{c}$, there is no transmission into the cladding as the ray remains reflected in the core of the optical fibre. Where $\mathbf{n}_{1}, \mathbf{n}_{2}$ represent the refractive indexes of core and cladding respectively, $\boldsymbol{\varphi}_{1}<\boldsymbol{\varphi}_{2}$ represents the angles of incidence and angles of refraction, while $\varphi_{c}$ represents the critical angle of the incident ray.

The propagation of light rays in optical fibre makes it the ideal for transmission over long distances. Table 3.1 shows the basic different types of fibre optic cables and their applications. 
Table 3. 1 Basic Cable types and Characteristics

\begin{tabular}{|l|c|c|c|l|}
\hline Type & $\begin{array}{c}\text { Core } \\
\text { diameter }\end{array}$ & $\begin{array}{c}\text { Cladding } \\
\text { diameter }\end{array}$ & $\begin{array}{c}\text { Refractive index } \\
\text { relative difference }\end{array}$ & Application \\
\hline 9/125(Single mode SI) & $\sim 9$ & 125 & $0.1-0.2$ & $\begin{array}{l}\text { Long Distances and High Bit } \\
\text { rates (Long Haul) }\end{array}$ \\
\hline $50 / 125$ (Multi mode GI) & 50 & 125 & $1-2$ & $\begin{array}{l}\text { Moderate Distances and Bit } \\
\text { rates }\end{array}$ \\
\hline $\begin{array}{l}\text { 62.5/125(Multi mode } \\
\text { GI) }\end{array}$ & 62.5 & 125 & $1-2$ & Local Area Networks \\
\hline \begin{tabular}{l} 
100/140(Multi mode SI) \\
\hline
\end{tabular} & 100 & 140 & $1-2$ & $\begin{array}{l}\text { Reduced distances in local area } \\
\text { networks }\end{array}$ \\
\hline
\end{tabular}

\subsection{The Capacity and Coverage area of Submarine Cables in Nigeria}

In the midst of an unending network of Global undersea cables, Nigeria has an impressive robust network of undersea cables all landing on the south west coast of Lagos with a combined bandwidth capacity of 14.9 Tbps. These five cables namely Ace, Main one, Glo 1, Sat-3/SAFE, and WACS are all responsible for the transmission of over $70 \%$ of the communication going in and out from Nigeria. The deployment of all these number of cables, each with a substantial bandwidth capacity has created a competitive atmosphere which has seen broadband pricing and rates gradually dwindle over the years. However despite the enormous bandwidth being provided by these undersea cables, Nigeria still suffers broadband underutilization as broadband penetration is currently at 21 percent.

Table 3. 2 Nigerian Undersea Cables Landed Capacity and Location

\begin{tabular}{|l|l|l|l|l|}
\hline S/N & Name & Capacity & Landing Location & Status \\
\hline 1 & ACE & $5.12 \mathrm{tps}$ & Lagos & Active \\
\hline 2 & MAIN ONE & $1.90 \mathrm{tps}$ & Lagos & Active \\
\hline 3 & GLO-1 & $2.50 \mathrm{tbps}$ & Lagos & Active \\
\hline 4 & SAT3/WASC & $340 \mathrm{gbps}$ & Lagos & Active \\
\hline 5 & WACS & $5.12 \mathrm{tbps}$ & Lagos & Active \\
\hline
\end{tabular}

Source: Nigerian National Broadband Plan 2013-2018 (2013)

\subsection{Role of Broadband in National Development}

The role of broadband cannot be overemphasized in economic development of any nation. It is proven that developing countries experience a growth of 1.3 percent in Gross Domestic Product for every 10 percent increase in broadband penetration Williams (2013). Table shows data of countries with High Human Development Index with Countries with Low Human Development Index according to the 2016 Human Development Report of the United Nations Development Program (UNDP). From the table it becomes obvious that countries with high internet penetration continue to experience high gross national income and high human development. Unfortunately Nigeria falls into the category of low per capita income due to its low internet penetration. 
Table 3. 3 Human Development Report 2016

\begin{tabular}{|c|c|c|c|c|}
\hline Rank & $\begin{array}{lcl}\text { VERY HIGH } & \text { HUMAN } \\
\text { DEVELOPMENT } & \\
\end{array}$ & $\begin{array}{l}\text { Gross national income } \\
(\mathrm{GNI}) \text { per capita }(\$)\end{array}$ & $\begin{array}{l}\text { Human } \\
\text { Development Index }\end{array}$ & $\begin{array}{c}\text { Internet Penetration } \\
(\%)\end{array}$ \\
\hline 1 & Norway & 67,614 & 0.949 & 97.2 \\
\hline 2 & Australia & 42,822 & 0.939 & 89.8 \\
\hline 2 & Switzerland & 56,364 & 0.939 & 89.41 \\
\hline 4 & Germany & 45,000 & 0.926 & 89.65 \\
\hline 5 & Denmark & 44,519 & 0.925 & 96.97 \\
\hline 5 & Singapore & 78,162 & 0.925 & 81.00 \\
\hline 7 & Netherlands & 46,326 & 0.924 & 90.41 \\
\hline 8 & Ireland & 43,798 & 0.923 & 82.17 \\
\hline 9 & Iceland & 37,065 & 0.921 & 98.24 \\
\hline 10 & Canada & 42,582 & 0.920 & 89.84 \\
\hline 10 & United States & 53,245 & 0.920 & 76.18 \\
\hline \multicolumn{5}{|c|}{ VERY LOW HUMAN DEVELOPMENT } \\
\hline 148 & Swaziland & 7,522 & 0.541 & 28.57 \\
\hline 149 & Syrian Arab Republic & 2,441 & 0.536 & 31.87 \\
\hline 150 & Angola & 6,291 & 0.533 & 13.00 \\
\hline 151 & Tanzania & 2,467 & 0.531 & 13.00 \\
\hline 152 & Nigeria & 5,443 & 0.527 & 25.67 \\
\hline 153 & Cameroon & 2,894 & 0.518 & 25.00 \\
\hline 154 & Papua New Guinea & 2,712 & 0.516 & 9.60 \\
\hline 154 & Zimbabwe & 1,588 & 0.516 & 23.12 \\
\hline 156 & Solomon Islands & 1,561 & 0.515 & 11.00 \\
\hline 157 & Mauritania & 3,527 & 0.513 & 18.00 \\
\hline 158 & Madagascar & 1,320 & 0.512 & 4.71 \\
\hline
\end{tabular}

Source: UNDP HDR 2016

\subsection{Strategies for Broadband Development}

In this paper, useful steps on how to maximize some of the opportunities being made available by the current innovations in broadband access are provided, as well as useful suggestions that may be helpful in overcoming some of the challenges being presented in the previous sections.

\subsection{Need for Public Sensitization}

The importance of informing the general public on the essence and service opportunities of fibre broadband cannot be over emphasized. Unlike power lines that everyone understands the purpose for which it is installed and collectively protect it from vandals, the average Nigerian knows that if his powerline or transformer is tampered with by unauthorized persons he/she will suffer the consequences by having to stay without electricity supply until the situation is rectified. Thus they readily accost anyone they see engaging in any activity around the power system. However, most Nigerians do not know what fibre optic cables are, how they work, and why they are so important and should be protected. Proper sensitization is needed as we have with both electric power distribution and oil and gas pipelines, to make people understand that cutting one single fibre optic cable could result to a total shutdown of communication activities in a region. Which is not only counterproductive but can also result in serious casualties should an emergency situation arise in such region. The government alone cannot protect the entire span of cables across the country but by making people realize that it is a collective responsibility to protect broadband infrastructure, they will appreciate the importance of such infrastructure.

\subsection{Need for Digital Literacy}

Despite Nigeria being often referred to as "The Giant of Africa" a lot of Nigerians are yet to come to terms with the use of broadband services such as video calling, e banking, e health, e commerce etc. despite having these services already being made available to them by telecommunications operators. Most persons are biased when it comes to digital services and feel that the use of digital services exposes them to become victims of fraudsters, stalkers, robbers and kidnappers hence they completely shun the use of such services. For proper utilization of broadband in Nigeria, digital literacy of citizens must be encouraged through campaigns and training programmes. Also the actual use of digital services should be enforced by both government agencies at all levels and private establishments to help more persons get conversant and acquainted with broadband services which in turn helps to reduce the digital divide. 


\subsection{Stringent Laws and Fines to Protect Assets and Infrastructure}

To help curb the incessant vandalization and destruction of broadband infrastructure, the government at federal and state levels should pass and enforce stronger laws that prohibit unauthorized access to telecommunications infrastructure with heavier fines to serve as a deterrent to would be culprits. These laws should be made public so that the general public would be aware that any persons caught would face severe punishment.

\subsection{Expansion and Promotion of Fibre Optic Last Mile Networks}

Last mile networks ensure broadband connectivity to the end user. Fibre optic last mile network deployment is still not widely recognized and is only used by multinationals, government agencies, banks and universities (Oboyerulu et al, 2017). In Nigeria, last mile connectivity is primarily achieved using wireless connectivity, which is propagated by the increase in the use of mobile devices by end users. The promotion of fibre optic last mile connectivity using FTTH and FTTC technology will not only boost broadband penetration in rural areas but will avail rural dwellers the opportunity to remain competitive and up to date with social and economic activities as their counterparts in urban areas.

\subsection{Government Participation in Creation of National Backbone}

There is need for both public and private partnerships between the government and telecommunications operators in ensuring that Nigeria has an interconnected national backbone. The present cost of right of way, taxation and other issues raised in the previous chapter all contribute to inflate the difficulties encountered by telecommunication network companies in laying fibre optic cables across the country. The government needs to partner directly with these companies and share equity with these companies in fibre optic cable ownership. Rather than having multiple pockets and clusters of fibre broadband across the country, a more collective approach would allow these companies to interconnect their individual fibre infrastructure with each other. Thereby ensuring that all existing multiple infrastructure can function as one strong national backbone with sufficient redundant links.

\section{Proposed Model for Maximizing Bandwidth Penetration in Nigeria}

In order to archive optimal broadband penetration and resolve the issues created by the lack of an interconnected fibre network, a new model has to be implemented which takes into account the peculiar challenges currently facing the telecommunications industry and resolves them with the following features;

1. Extension of undersea cable landing points to Port Harcourt

2. Creation of long haul feeder networks to transverse the entire country

3. Establishment of hubs or central stations that monitor and create access to feeder network.

4. Establishment of local stations which create access to multiple metropolitan networks.

5. Ensure network survivability at event of fibre cut or equipment malfunction

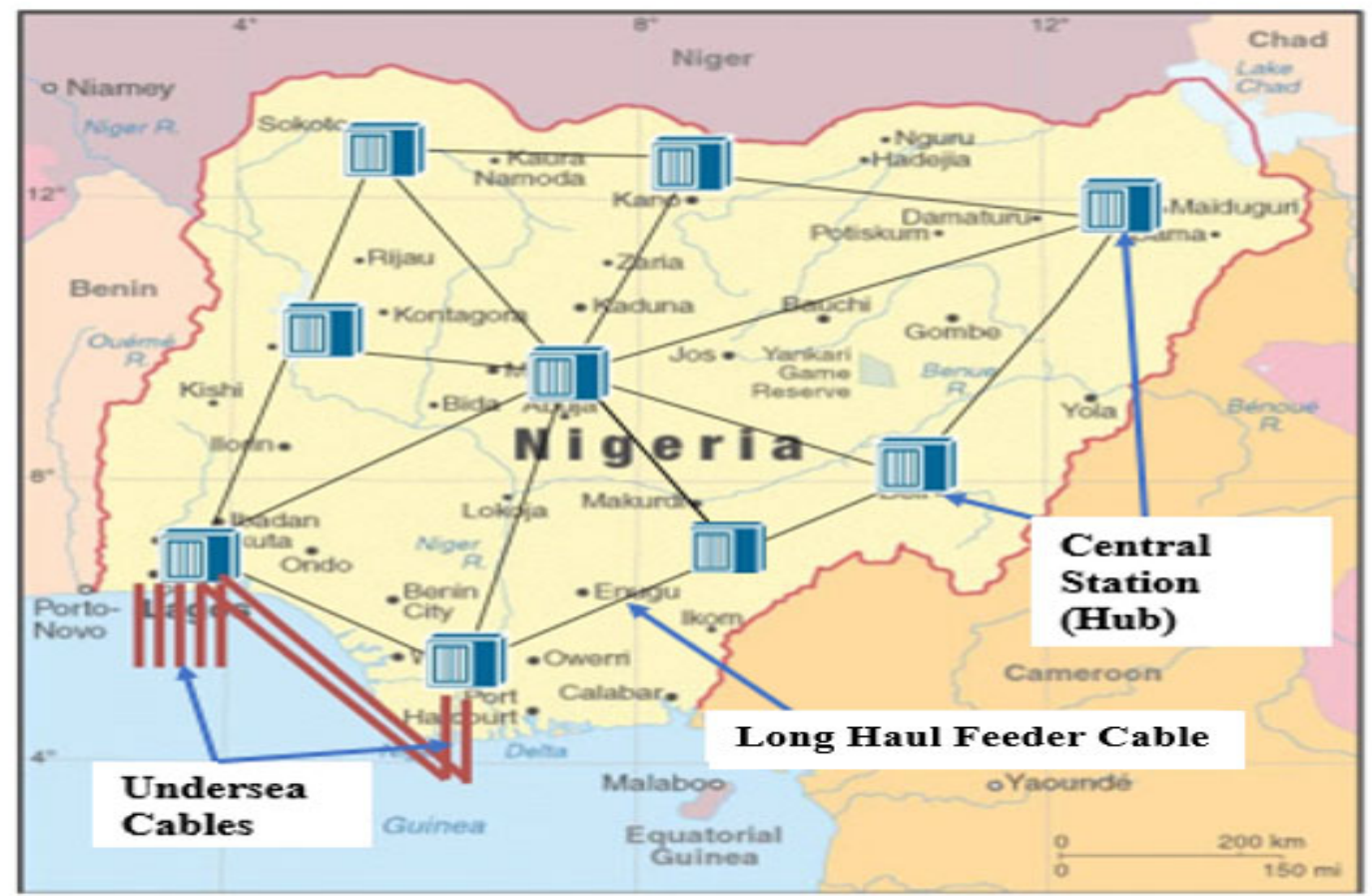

FIGURE 5. 1 Proposed Architecture for Interconnected Backbone 


\subsection{Cost Implication of Proposed Model}

In calculating cost requirements, the following assumptions were made the estimated cost per Km for installing a long haul feeder cable was estimated at \$6,000 USD per $\mathrm{km}$ according to build out cost for fibre optic infrastructure in Nigeria (Nigerian National Broadband Plan 2013- 2018, 2013). It was assumed that ROW taxes where waived by the Federal Government or paid for through special interventions by the Federal Government to affected State since this domestic backbone is a national asset.

Table 5. 1 Cost of Installing Long Haul Cables

\begin{tabular}{|l|l|l|l|}
\hline S/N & Route & Distance (KM) & Cost (USD \\
\hline 1 & Lagos to Port Harcourt & 617.4 & $3,704,400$ \\
\hline 2 & Lagos to Abuja & 760.7 & $4,564,200$ \\
\hline 3 & Lagos to Minna & 620.6 & $3,723,600$ \\
\hline 4 & Port Harcourt to Abuja & 669.7 & $4,018,200$ \\
\hline 5 & PHC to Abakiliki & 287.9 & $1,727,400$ \\
\hline 6 & Minna to Abuja & 160.2 & 961,200 \\
\hline 7 & Minna to Sokoto & 633.7 & $3,802,200$ \\
\hline 8 & Sokoto to Abuja & 670.7 & $4,024,200$ \\
\hline 9 & Sokoto to Kano & 529.2 & $3,175,200$ \\
\hline 10 & Kano to Abuja & 441.6 & $2,649,600$ \\
\hline 11 & Kano to Maiduguri & 588.0 & $3,528,000$ \\
\hline 12 & Maiduguri to Abuja & 843.2 & $5,059,200$ \\
\hline 13 & Maiduguri to Jalingo & 443.0 & $2,658,000$ \\
\hline 14 & Jalingo to Abuja & 600.2 & $3,601,200$ \\
\hline 15 & Abuja to Abakiliki & 516.4 & $3,098,400$ \\
\hline 16 & Abakiliki to jalingo & 535.8 & $3,214,800$ \\
\hline & Total & 8918.3 & $53,509,800$ \\
\hline
\end{tabular}

Total Estimated Cost of installing entire Long Haul Cables $=\$ 53,509,800$

Table 5. 2 Operational Cost

\begin{tabular}{|l|l|l|}
\hline $\mathrm{S} / \mathrm{N}$ & Item & Long Haul per KM \\
\hline 1 & Fibre Rebuild & $\$ 12,000$ \\
\hline 2 & Fibre Replace & $\$ 2400$ \\
\hline 3 & Maintenance & $\$ 620$ \\
\hline & Total & $\$ 15,020$ \\
\hline
\end{tabular}

Operational cost for entire Long Haul Network $=\$ 15,020 \times 8918.3=\$ 133,952,866$

\subsection{Economic Implication of Proposed Model}

The implementation of this proposed model will not only mean having an organized domestic interconnected network but will also increase broadband penetration. A gradual 10 percent annual growth in broadband penetration will ensure that Nigeria achieves over 70 percent broadband penetration by 2022 (Figure 4.2). This development will also result in a cumulative increase by 6.6 percent in the gross domestic product of Nigeria by 2022. 


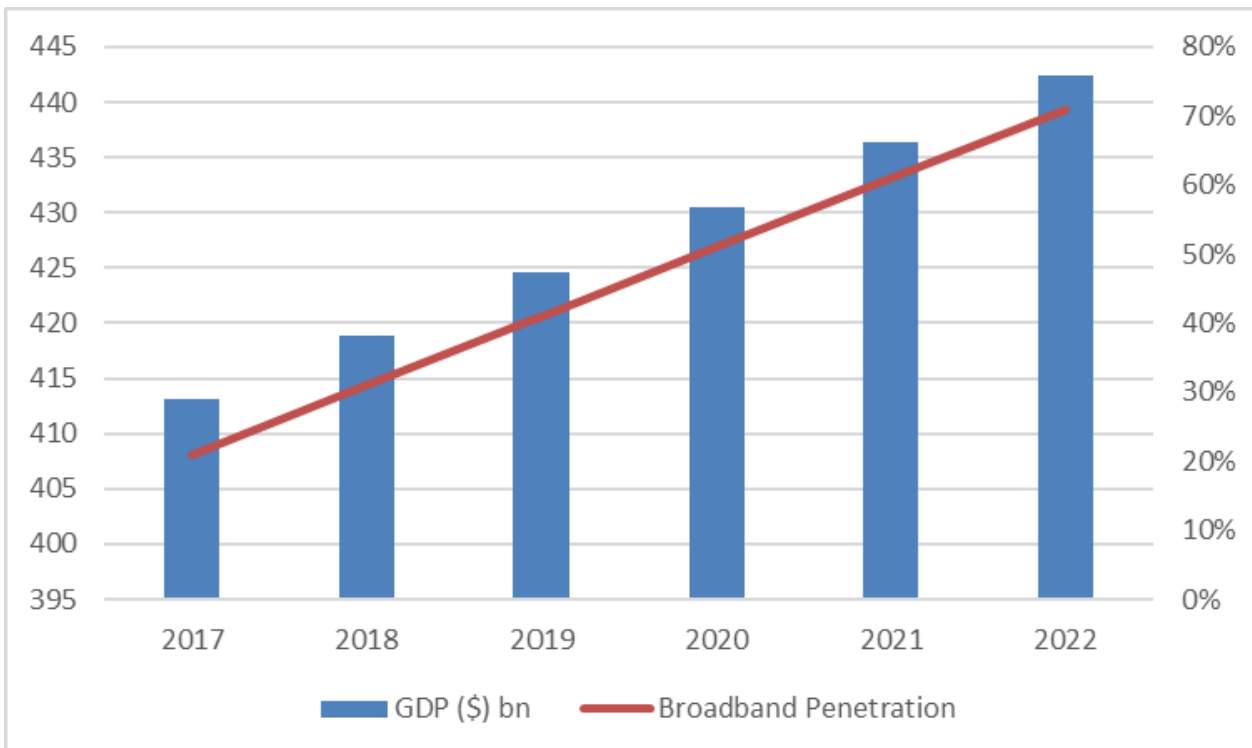

FIGURE 5. 2 Economic Forecast for Broadband Development in Nigeria

\subsection{Benefits of Proposed Architecture}

1. This proposed model cuts down on cost of laying cables by network operators by allowing them connect to the nearest central station closest to the proposed location rather than having to begin laying cables from the landing points in Lagos.

2. It avails all existing and incoming telecommunication companies the opportunity to get access to bandwidth at an effect cost based price.

3. It serves as an investment vehicle for both the federal government and telecommunications operators.

4. It eliminates issues of multiple taxation as the feeder network is under the supervision of the federal government and is treated as a national asset.

5. Extension of landing points to Port Harcourt reduces pressure on Lagos fibre optic networks and also helps to ensure network protection as the network is being supplied bandwidth from multiple landing points in different locations.

6. Fibre services such as FTTH, FTTC are easily accessible as customers will only have to connect to the nearest local station.

7. Improved broadband coverage and user experience for end users irrespective of location.

\subsection{Conclusion}

The current existing realities have proven that access to information is essential for any nation to attain global recognition in socio - economic development, financial relevance, military dominance, educational prominence and health advancement. Undersea cables have already provided a gateway for high speed connectivity to the rest of the world. However the pertinent issues surrounding the affordability and access to broadband must be carefully addressed to ensure that the efforts made so far are not in vain. Fibre broadband if allowed to develop, can provide the mechanism needed for improved standard of living by motivating digital literacy among end users.

\section{REFERENCES}

Africa Coast to Europe [online] Available at https://www.ace-submarinecable.com/ace/default/EN/all/ace_fr/ [Accessed 26 Feb.2018]

Alexandra C. (2013). Why undersea internet cables are more vulnerable than you think [online] Available at https://www.wired.com/2013/04/how-vulnerable-are-undersea-internet-cables/ [Accessed 22 Feb.2018]

Ariyo A. O., Seluwa O.E. \& Olaojoyetan M.C. (2014). Fibre broadband development in Nigeria: a catalyst to economic growth and social development, Global Advanced Research Journal of Engineering, Technology and Innovation (ISSN: 2315-5124) Vol. 3(5) pp. 083-099, July, 2014

Ariyo A. O. \& Olaojoyetan M.C. (2013). The poor state of broadband in Nigeria: an impediment to national development and globalisation. Academic Journal of Interdisciplinary Studies.

Commonwealth Telecommunications Organization (2012) The socio-economic impact of broadband in subSaharan Africa: the satellite advantage [online] Available at http://www.cto.int/media/research/projects/Socio- 
Economic_Impact_of_Broadband_The_Satellite_Advantage.pdf [Accessed 26 Feb.2018]

EMPEA (2014), Case study: main one cable company (Africa) Emerging Markets Private Equity Association [online] Available at https://www.empea.org/app/uploads/2017/03/EMPEA_Case_Study_Main_One.pdf [Accessed 26 Feb.2018]

Forden E. (2015). The Undersea Cable Boom in Sub-Saharan Africa, USITC Executive Briefing on Trade [online] Available https://www.usitc.gov/publications/332/executive_briefings/forden_submarine_cables_june2015.pdf [Accessed 22 Feb.2018]

Geere D. (2011). How the first cable was laid across the Atlantic [online] Available at http://www.wired.co.uk/article/transatlantic-cables [Accessed 26 Feb.2018]

Human Development Report (2016). United Nations Development Program [online] Available at http://hdr.undp.org/en [Accessed 26 Feb.2018]

Kazeem Y. (2016). It's The Data: Nigeria's mobile data prices are finally starting to come down, Quartz Africa [online] Available at https://qz.com/691930/nigeria-could-be-on-the-verge-of-a-mobile-data-pricerevolution [Accessed 26 Feb.2018]

Jensen M. (2006). Lowering the Costs of International Bandwidth in Africa [Online] Available at http://ent.arp.harvard.edu/AfricaHigherEducation/Reports/open_access_EN.pdf[Accessed 26 Feb.2018]

Nigerian Communications Commission (2013) Open access model for next generation optic fibre broadband network the Nigerian model [online] Available at https://www.ncc.gov.ng/documents/470-eoi-invitationfor-comments-on-open-access-model-for-next-generation-optic-fibre-broadband-network/file [Accessed 26 Feb.2018]

Nigerian National Broadband Plan 2013- 2018 (2013) [online] Available at https://www.researchictafrica.net/countries/nigeria/Nigeria_National_Broadband_Plan_2013-2018.pdf [Accessed 22 Feb.2018]

Oboyerulu E. A., Simon O. A. \& Ndujiuba C.U. (2017). State of fiber optic networks for internet broadband penetration in Nigeria - a review, International Journal of Optoelectronic Engineering p-ISSN: 21677301, e-ISSN: 2167-731X, 2017; Vol 7(1): pp1-12. [online] Available at http://article.sapub.org/10.5923.j.ijoe.20170701.01.html [Accessed 22 Feb.2018]

Senior J. M. (2009). Optical Fiber Communications Principles and Practice, Pearson Education Limited, ISBN: 978-0-13-032681-2. [online] Available at https://eceagmr.files.wordpress.com/2014/09/optical-fibercommunications-principles-and-pr.pdf [Accessed 22 Feb.2018]

Shu-Kun H., Jackie K., Chung-Liang L., Ching-Hui T., Wen-Bin D.,Chia-Yen Ku, \& Jean-Claude S. (2008). Turbidity currents, submarine landslides and the 2006 Pingtung earthquake off SW Taiwan, Terrestrial, Atmospheric and Oceanic Sciences (TAO). Vol. 19, No. 6, 767-772, December 2008

Vertiv (2010). West Africa Cable System (WACS), A Vertiv Case Study [online] Available at https://www.vertivco.com/globalassets/products/facilities-enclosures-and-racks/integrated-solutions/wacscs-en-gl-is-01616 117082 0.pdf [Accessed 26 Feb.2018]

Williams S. (2013). Fiber broadband: a foundation for social and economic growth [online] Available at http://www3.weforum.org/docs/GITR/2013/GITR_Chapter1.5_2013.pdf [Accessed 26 Feb.2018]

Wikipedia (2017). Satellite internet access [online] Available at https://en.wikipedia.org/wiki/Satellite Internet_access [Accessed 26 Feb.2018]

Wikipedia (2017). Submarine communications cable [online] Available at https://en.wikipedia.org/wiki/Submarine_communications_cable [Accessed 26 Feb.2018]

Wikipedia (2017). Refraction [online] Available at https://en.wikipedia.org/wiki/Refraction [Accessed 26 Feb.2018] 